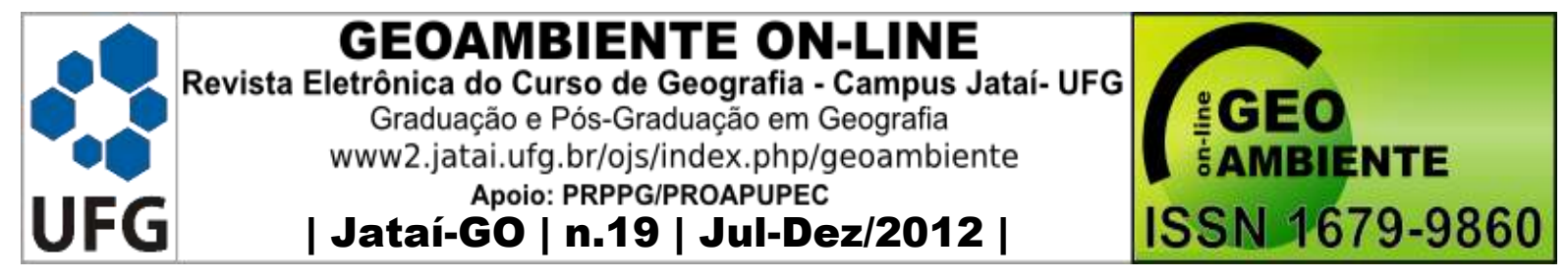

\title{
UMA ANALISE DA MAIOR EPIDEMIA DE DENGUE CLÁSSICA ACONTECIDA NA CIDADE DE CUIABÁ-MT
}

\author{
Romário Rosa de Sousa ${ }^{1}$, Moema Couto Silva Blatt ${ }^{2}$, José Abel do Nascimento ${ }^{2}$ \\ (1 - Universidade Federal do Mato Grosso. Departamento de Geografia - Campus \\ Universitário do Araguaia, Prof. MSc, romarioufg@yahoo.com.br, 2 - Instituto Focus \\ Educação - IFE, romarioufg@yahoo.com.br)
}

\section{Resumo}

O primeiro caso de dengue clássica em Cuiabá-MT foi registrado no ano de 1991, mas a maior epidemia aconteceu no ano de 2009, quando foram registrados aproximadamente 11.207(onze mil duzentos e sete) casos notificados. Desse total, 90\% foram de dengue clássica, $7 \%$ referiram-se aos casos graves e 3\% referiram-se aos casos de óbito. Considerando esses dados, este trabalho teve como objetivo principal analisar a maior epidemia de dengue clássica acontecida na cidade de Cuiabá-MT, no ano de 2009. Os procedimentos metodológicos adotados se pautaram em 4 (quatro) etapas distintas, sendo a primeira etapa destinada à obtenção dos dados meteorológicos junto ao 9DISME/INMET; a segunda etapa destinada à coleta de dados cedidos pela Secretaria Municipal de Saúde SMS/Centro de Controle de Zoonoses (CCZ) de Cuiabá - MT; a terceira etapa dedicada à obtenção dos dados via sistema SINAN/DATASUS; e a quarta etapa correspondeu às análises e discussões sobre o tema. Constatou-se, na análise empreendida, que nos meses de abril, com 4.534, e maio, com 3.121 casos, foram registrados os maiores números de notificações relacionados à dengue clássica na cidade de Cuiabá-MT, coincidindo este período com o início do outono, imediatamente posterior ao período chuvoso, verão. Os dados diminuíram bruscamente nos meses de junho a outubro, voltando a aumentar as confirmações de dengue nos meses de novembro e dezembro. Dessa forma, visualizou-se que os casos de dengue clássica variam de acordo com as condições atmosféricas.

Palavras-chaves: dengue, Cuiabá, precipitação, casos.

\section{Abstract}

Artigo recebido para publicação em 26 de Abril de 2012

Artigo aprovado para publicação em 22 de Novembro de 2012 


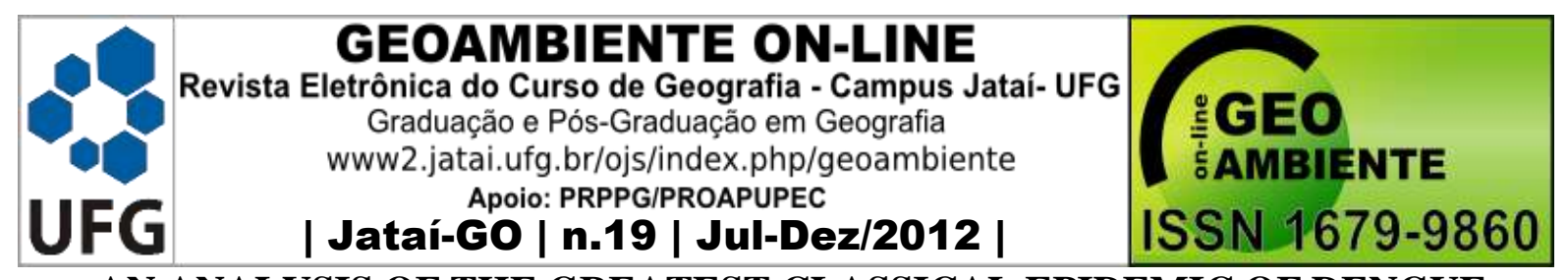

AN ANALYSIS OF THE GREATEST CLASSICAL EPIDEMIC OF DENGUE HAPPENED IN CUIABÁ-MT

The first case of classic dengue in Cuiabá-MT was registered in the year of 1991, but the largest epidemic occurred in the year of 2009, when were registered approximately 11,207 (eleven thousand two hundred and seven) reported cases. Of this total, 90\% were of classic dengue, $7 \%$ referred of serious cases and 3\% referred of death cases. Considering these data, this study had as the main objective analyze the largest epidemic of classic dengue happened in the city of Cuiabá-MT, in the year of 2009. The methodological procedures adopted were based on 4 (four) distinct steps, being the first step to obtain the meteorological data from the $9^{\text {th }}$ DISME/INMET; the second step was for the collect of data provided by the Municipal Health City hall - SMS / Center of Zoonosis Control (CCZ) of Cuiabá-MT, the third step was dedicated to obtain data through the system SINAN/ DATASUS; and the fourth step corresponded to analyzes and discussions on the subject. We found that, in the analysis done, that in the months of April, with 4,534, and May, with 3,121 cases, it were registered the highest number of notifications related to classic dengue in the city of Cuiabá-MT, coinciding this period with the beginning of autumn, immediately after the rainy season, summer. The data fell sharply in the months of June to October, increasing the confirmations of dengue in the months of November and December. Thus, it was visualized that the cases of classic dengue vary accordingly to the atmosphere conditions.

Key words: dengue, Cuiabá, precipitation, cases.

\section{Resumen}

UNA REVISIÓN DE LA MAYOR EPIDEMIA DE DENGUE EN LA CIUDAD DE CUIABÁ-BRASIL

El primer caso de dengue clásico en Cuiabá-Brasil fue detectado en el año de 1991, pero la epidemia más grande ocurrió en el año 2009, cuando registraron cerca de 11.207 casos de la enfermedad. De este total, $90 \%$ fueron de dengue clásico, $7 \%$ se han referido a los casos graves y $3 \%$ casos de muerte. Teniendo en cuenta estos datos, este trabajo tuvo como objetivo principal analizar la mayor epidemia de dengue clásico en la ciudad de Cuiabá - Brasil, en el año 2009. Los procedimientos metodológicos utilizados si siguen en 4 (cuatro) distintos pasos, el primer paso para obtener los datos del tiempo en la DISMEINMET 9; el segundo paso para la recogida de los datos en la Secretaria Municipal de Saúde - SMS/ Centro de 


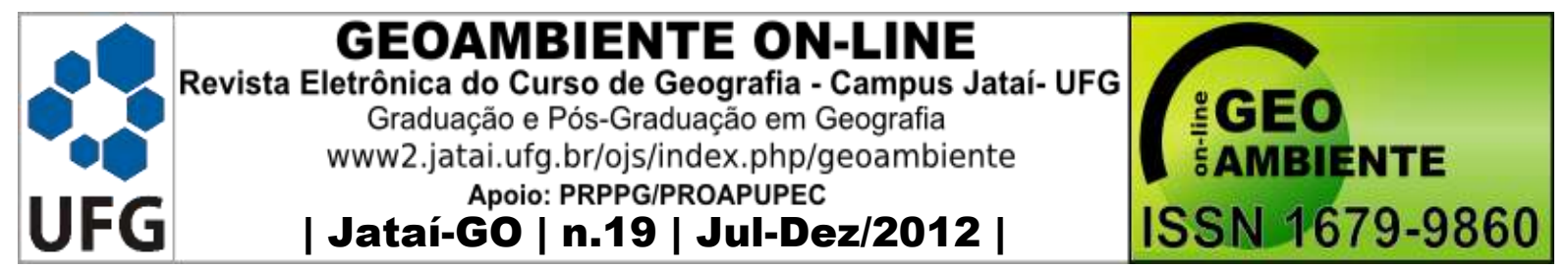

Controle de Zoonoses (CCZ) de Cuiabá- Brasil; el tercer paso se dedica a obtener los datos a través del sistema SINANDATASUS; y el cuarto paso correspondía a los análisis y debates sobre el tema. Se observó, en el análisis, que en el meses de abril, con 4.534 y mayo, con 3.121 casos, se registraron el mayor número de notificaciones relacionado con la enfermedad de dengue en la ciudad de Cuiabá-Brasil, este período coincidió con el inicio del otoño, inmediatamente después de la temporada de lluvias, verano. Los datos han disminuido considerablemente en los meses de junio a octubre, volviendo a aumentar las confirmaciones de casos de dengue en los meses de noviembre y diciembre. De esta manera, se prevé que los casos de dengue clásico varían según las condiciones climáticas.

Palabras clave: precipitación, dengue, Cuiabá, casos.

\section{Introdução}

Segundo Tauil (2002), a dengue é hoje a arbovirose mais importante do mundo. Cerca de 2,5 bilhões de pessoas encontram-se sob o risco de se infectarem, particularmente em países tropicais como o Brasil, onde as temperaturas e as umidades favorecem a proliferação do mosquito vetor. Entre as doenças reemergentes é a que se constitui em problema mais grave de saúde pública. São bem conhecidos sua etiologia e mecanismos de transmissão. O seu espectro clínico é amplo, variando de formas assintomáticas ou oligosintomáticas até formas graves e letais. As causas da ocorrência de formas graves ainda não estão plenamente estabelecidas, existindo algumas teorias que as relacionam à maior virulência da cepa de vírus infectante, à seqüência de infecções pelos diferentes sorotipos do agente etiológico, a fatores individuais do hospedeiro e a uma combinação de todas as explicações anteriores. (TAUIL, 2002).

Entre os fatores ambientais que interferem no desenvolvimento larvário destacam-se a temperatura, a luz, a salinidade, a presença de poluentes orgânicos e inorgânicos, o movimento da água, relações com a vegetação aquática, não aquática com produtos derivados de plantas e com microorganismos, predadores e parasitas presentes na água. (CONSOLI, 1994).

Nos centros urbanos, o modelo de reprodução social, pautado no estimulante consumo de produtos industrializados descartáveis exerce grande influência na produção de ambientes favoráveis à proliferação do vetor e disseminação do vírus da dengue, Malvasi (2007), relata que esse fator aliado à não disponibilidade de serviços de saneamento ambiental em 


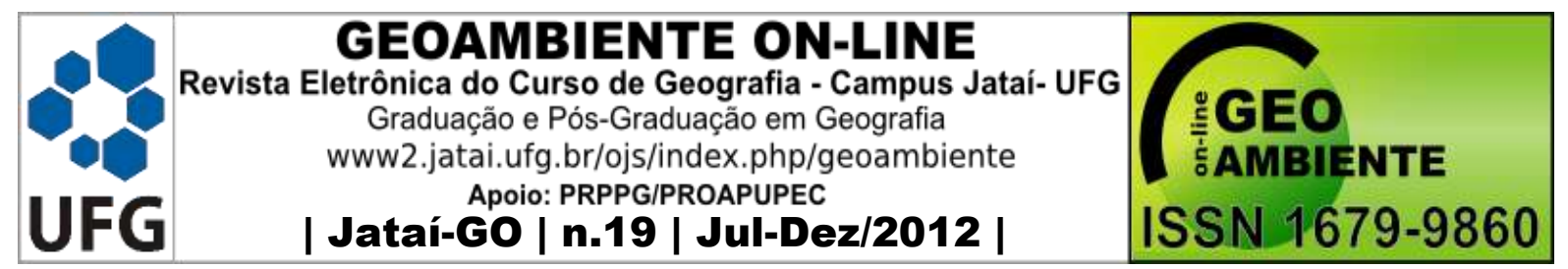

quantidade e qualidade adequadas (quanto ao acesso e frequência no abastecimento de água e coleta de lixo) tornam-se propícios à dinâmica de transmissão da doença. A precariedade na oferta desses serviços, principalmente quanto ao abastecimento de água, pode levar à adoção de práticas de estocagem em recipientes, que, por sua vez, podem figurar como potenciais locais de reprodução do vetor.

Os vínculos entre desenvolvimento, condições sócio-ambientais e de saúde são muito estreitos. A forma como a sociedade utiliza o espaço e modifica a paisagem interfere na produção das doenças (DONALISIO, 1999; SILVA, 1997; PIGNATTI, 1996).

O processo de ocupação do espaço em todas as fases do desenvolvimento humano reflete-se no seu futuro, sendo parte inerente aos determinantes das condições de vida. Para explicar a organização atual do espaço é necessário reconhecer sua inter-relação com o tempo. Uma vez que o meio em algum momento já foi alterado pela ação humana e, portanto, já não era natural, caberia recorrer a alguma forma de compreensão do comportamento humano. (PESSOA, 1978, p. 153).

As doenças que aparecem em curto espaço de tempo e que são rapidamente transmitidas para os seres humanos causam inúmeros agravos para a saúde pública. Doenças virais, como as do aparelho respiratório (gripe, sarampo) e as transmitidas por vetores (dengue, febre amarela, malária e outras), cujas incidências estão ligadas simplesmente às condições climáticas e ao saneamento básico. (GUNN, 2004).

Como enfatizou o Sistema Único de Saúde - SUS - e o Ministério da Saúde (2010), no Brasil, 70\% dos casos de dengue se concentram entre janeiro, fevereiro, março, abril e maio para os 26 estados e o Distrito Federal. O risco de epidemia aumenta em municípios de maiores portes e nas regiões metropolitanas. Vários Estados e municípios brasileiros estão em áreas de risco de transmissão desde o ano de 2001, sendo que o Estado de Mato Grosso se destaca com uma área de alto risco de transmissão.

Este trabalho teve como objetivo principal analisar a maior epidemia de dengue clássica acontecida na cidade de Cuiabá-MT no ano de 2009 em abordagem sistêmica.

\section{Metodologia}

O Estado de Mato Grosso está localizado entre as coordenadas geográficas de latitudes $7^{\circ}$ a $18^{\circ}$ sul e longitudes $50^{\circ}$ a $62^{\circ}$ oeste de Greenwich. As altitudes variam de 100 a 1.200 metros, no centro do Continente Sul Americano (Figura 1). 


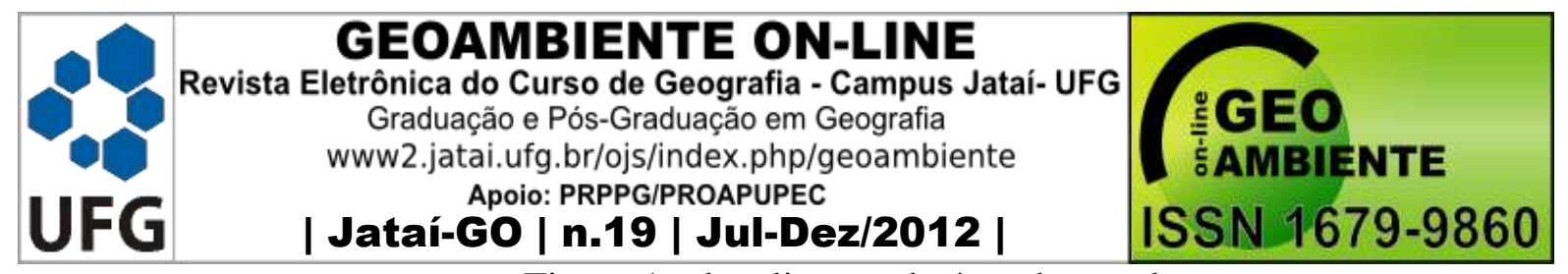

Figura 1 - localização da área de estudo

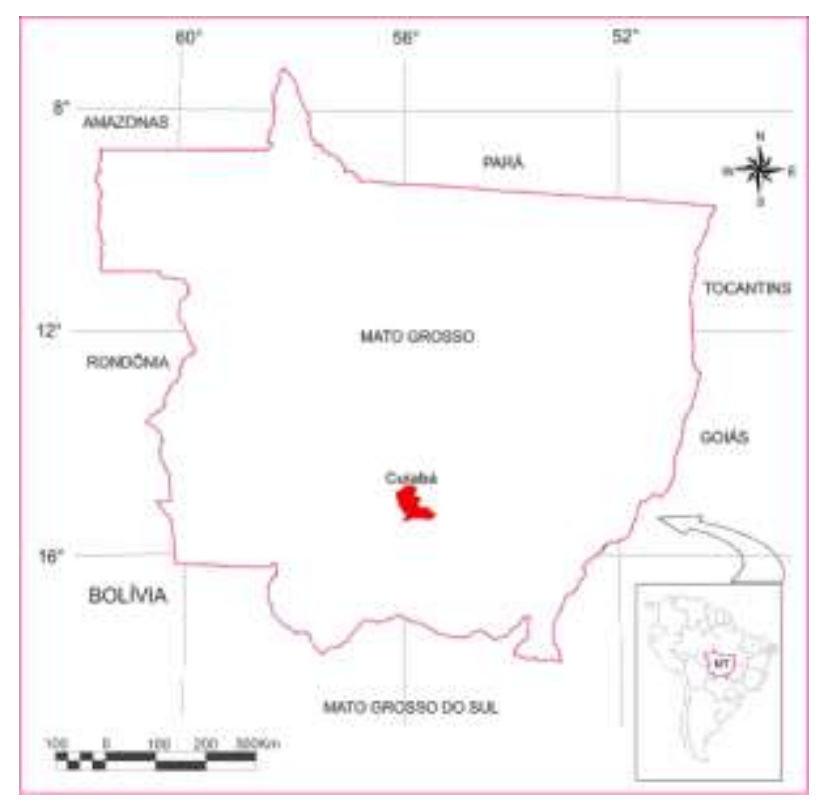

O município de Cuiabá, capital do estado de Mato Grosso, localiza-se na mesorregião norte-mato-grossense, na microrregião formada pelos Municípios de Chapada dos Guimarães, Cuiabá, Nossa Senhora do Livramento, Santo Antônio de Leverger e Várzea Grande. A sede municipal está situada a altitude de 165 metros nas coordenadas geográficas $15^{\circ} 35^{\prime} 56^{\prime \prime}$ de latitude sul (S) e 5606’01'” de longitude oeste (W) de Greenwich (Gr) (CUIABÁ, 2009).

O sítio urbano possui uma área total de $3.224,68 \mathrm{Km}^{2}$ e a população é de 542.861 pessoas, das quais $98,59 \%$ vivem na macrozona urbana, que é de 251,94 $\mathrm{Km}^{2}$ e subdividida em quatro administrações regionais (norte, sul, leste e oeste), possuindo 116 bairros cadastrados pela Prefeitura Municipal (CUIABÁ, 2009).

Com o objetivo de analisar a maior epidemia de dengue clássica acontecida na cidade de Cuiabá-MT, os procedimentos metodológicos se pautaram em 4 (quatro) etapas distintas: a $1^{\text {a }}$ etapa destinada à obtenção dos dados meteorológicos junto ao $9^{\circ} D I S M E / I N M E T ;$ a $2^{\text {a }}$ etapa foi destinada à coleta de dados cedidos pela Secretaria Municipal de Saúde SMS/Centro de Controle de Zoonoses - CCZ, de Cuiabá - MT; a $3^{\text {a }}$ etapa dedicada à obtenção dos dados via sistema SINAN/DATASUS; já a $4^{\text {a }}$ etapa correspondeu às análises e discussões sobre o tema. Em linhas gerais, o trabalho foi desenvolvido dentro da concepção de Besancenot(1997) apud Mendonça (2003); Guimarães (2000) e Sousa (2008).

Nos casos de dengue clássica, o Aedes aegypti se reproduz mais rapidamente em ambientes com temperaturas médias acima de $28^{\circ} \mathrm{C}$ e com uma umidade relativa do ar acima 


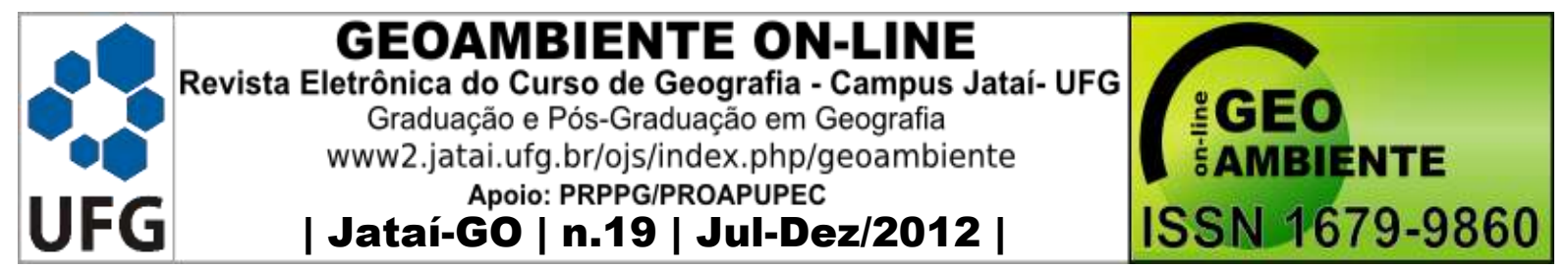

de $70 \%$. Nesse sentido, a temperatura e a umidade relativas médias diárias são os elementos climatológicos fundamentais no estabelecimento das correlações com as ocorrências de dengue.

\section{Resultados e Discussão}

O mosquito Aedes aegypti se distribui geograficamente entre os paralelos $45^{\circ}$ de latitude norte e $35^{\circ}$ de latitude sul (Figura 2), perfazendo uma área caracterizada por altas temperaturas e intensa pluviosidade em determinados períodos, além de uma significativa umidade do ar, fatores favoráveis à proliferação do mosquito (CATÃO, 2007).

Figura 2 - casos de dengue no mundo.

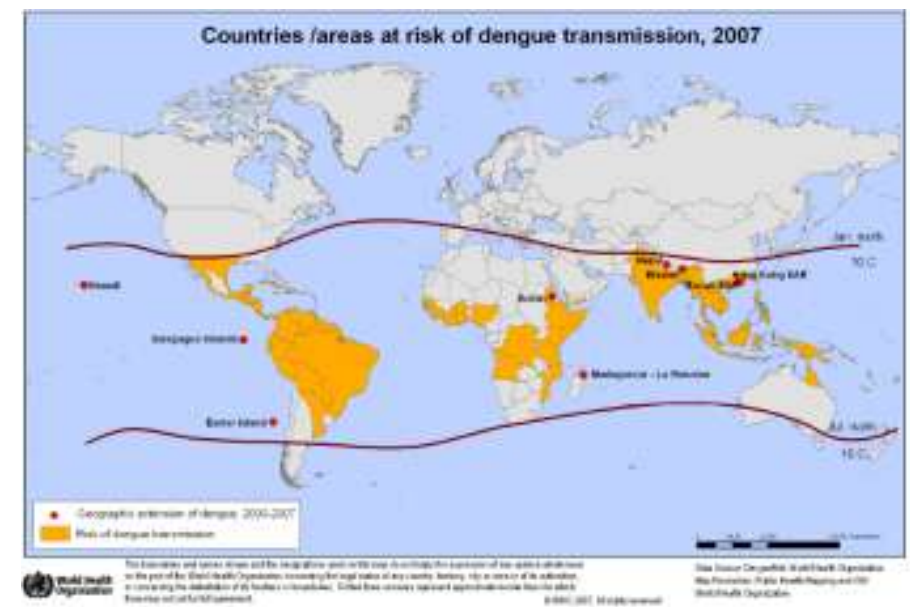

Fonte:http://gamapserver.who.int/mapLibrary/Files/Maps/World_DengueTrans mission_Extension_2007.png. Acesso em: 8/03/2012.

A distribuição asiática original do mosquito englobava o sudeste asiático, tendo a Cordilheira do Himalaia como limite norte. Entretanto, devido ao transporte passivo dos ovos e de formas imaturas em recipientes artificiais, passou a atingir outras regiões, como o Continente Americano, a África, a Europa Meridional e algumas ilhas do Oceano Pacífico, como o Arquipélago do Havaí. (ROSSI 1999).

A dengue é uma doença febril, infecciosa, aguda, causada por um vírus (Figura 3), transmitido principalmente pelo mosquito Aedes aegypti infectado. O vírus possui os sorotipos DENV1, DENV2, DENV3 e DENV4 e a doença pode evoluir sob as formas clássica, hemorrágica (FHD), com complicações ou a síndrome de choque da dengue (SCD), estas duas as formas mais graves (CUIABÁ, 2009). 


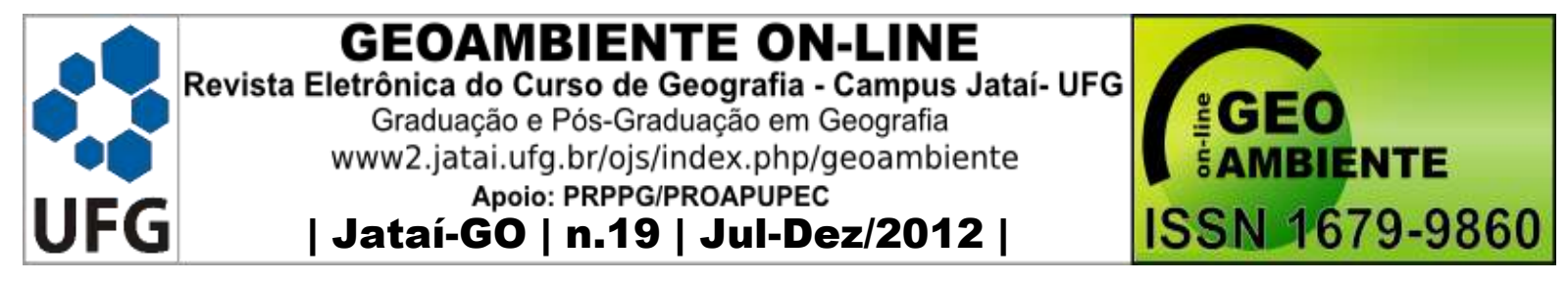

Figura 3 - Vírus da dengue

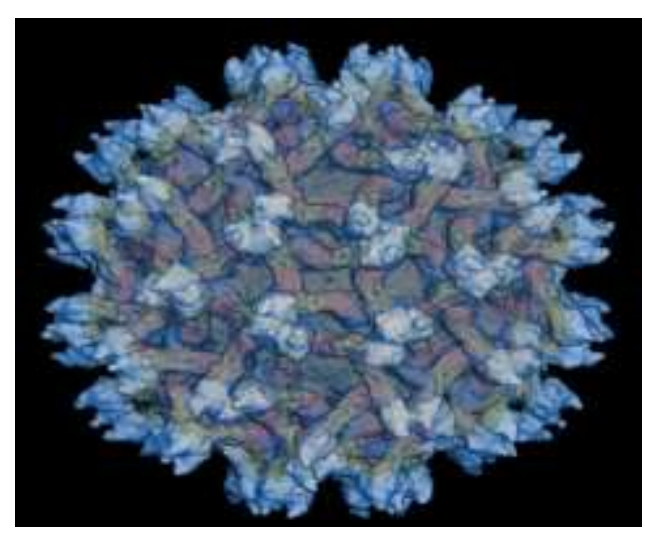

Fonte: Organização Panamericana da Saúde (2009).

A dengue clássica é um dos principais problemas de saúde pública no mundo. De acordo com a Organização Mundial da Saúde (OMS), estima-se que 2,5 bilhões de pessoas 2/5 da população mundial - estão sob o risco de contrair dengue e que ocorram anualmente cerca de 50 milhões de casos. Desse total, cerca de 550 mil necessitam de hospitalização e pelo menos 20 mil morrem em conseqüência da doença (BRASIL, 2009).

A primeira epidemia de dengue nas Américas, que foi confirmada por testes laboratoriais, ocorreu no Caribe e Venezuela nos anos de 1968/1969 e 1977, respectivamente. A partir da década de 1980 ocorreram epidemias na Bolívia, Paraguai, Equador, Cuba, e outros países da América Latina (NERES, 2009).

No Brasil, a primeira epidemia documentada clínica e laboratorialmente ocorreu de 1981 a 1982, em Boa Vista (RR), causada pelos sorotipos 1 e 4. Em 1986, ocorreram epidemias atingindo o Rio de Janeiro e algumas capitais da região Nordeste. Desde então, a dengue vem ocorrendo no Brasil de forma continuada, intercalando-se com a ocorrência de epidemias, geralmente associadas com a introdução de novos sorotipos em áreas anteriormente indenes e/ou alteração do sorotipo predominante (BRASIL, 2001).

Durante a década de 1990, ocorreu um aumento significativo da incidência de dengue clássica, sendo isso um reflexo da ampla dispersão do Aedes aegypti no território nacional. A presença do vetor, associada à mobilidade da população, levou à disseminação dos sorotipos DENV1 e DENV2 para 20 dos 26 estados do país (PIMENTA JUNIOR, 2004). Entre os anos de 1990 e 2000, várias epidemias foram registradas, sobretudo nos grandes centros das regiões Sudeste e Nordeste do Brasil, responsáveis pela maior parte dos casos notificados. As 


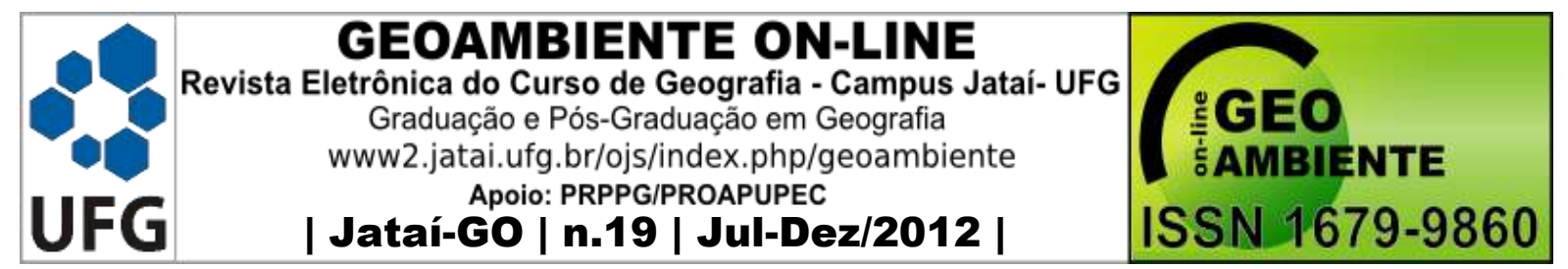

regiões Centro-Oeste e Norte foram acometidas mais tardiamente, com epidemias registradas a partir da segunda metade da década de 1990 (BRASIL, 2001).

Em 2008 foram notificados 585.769 casos e novas epidemias causadas pelo sorotipo DENV2 ocorreram em diversos estados do país, marcando o pior cenário da doença no Brasil. Essas epidemias foram caracterizadas por um padrão de migração de gravidade para as crianças, que representaram mais de 50\% dos pacientes internados nos municípios de maiores contingentes populacionais, assim mesmo em municípios com menor população, mais de $25 \%$ dos pacientes internados por dengue eram crianças. No ano de 2009, até a semana epidemiológica 17, foram notificados 266.285 casos de dengue (BRASIL, 2009).

Em Mato Grosso, os primeiros casos notificados foram a partir de 1991. Com isso, entre os anos de 2000 a 2009, observou-se um o aumento da doença com um crescimento dos casos graves, até mesmo levando as vítimas a óbitos. Para o ano de 2009, os casos graves apresentaram um pico de ocorrência e a letalidade se manteve acima das estimativas (MATO GROSSO, 2009).

Segundo a Secretaria Municipal de Saúde de Cuiabá-MT, o primeiro caso de dengue clássica registrada foi em 1991, e o primeiro episódio epidêmico se deu no ano de 1995 (MATO GROSSO, 2009). Assim em 2009, ocorreu a maior das epidemias no Estado de Mato Grosso, sendo que a cidade de Cuiabá se destacou com aproximadamente 11.207 (onze mil e duzentos e sete) (SINAN/DATASUS, 2011) casos de notificações, desse total $90 \%$ foram de dengue clássica, os casos graves somaram 7\% e de óbitos chegou-se a 3\% (CUIABÁ, 2009).

Observando a (tabela 1), referente ao ano de 2009, notou-se que a temperatura média se comportou de forma estável, com valores de 27,5 no mês de janeiro, em fevereiro, de 27,6, e, em março, de $27,6^{\circ} \mathrm{C}$. Vale ressaltar que estes trimestres correspondem ao verão no Cerrado, cujas características são temperaturas, umidade relativa do ar e precipitação elevadas, ou seja, o período chuvoso. Foi possível perceber, ainda, que os meses com as temperaturas médias menos elevadas foram os meses de abril, com 24,8, maio, 25,5 e junho, $\operatorname{com} 22,7^{\circ} \mathrm{C}$.

A partir do mês de julho, as temperaturas médias voltaram a se elevar, registrando $24,1^{\circ} \mathrm{C}$ em julho; 25,9 , em agosto; 27,2 , em setembro; 28,2 , em outubro; 28,4 , em novembro; e $28,0^{\circ} \mathrm{C}$ em dezembro. Diante disso, constatou-se que os meses de novembro, outubro e dezembro se destacaram como os mais quentes. 


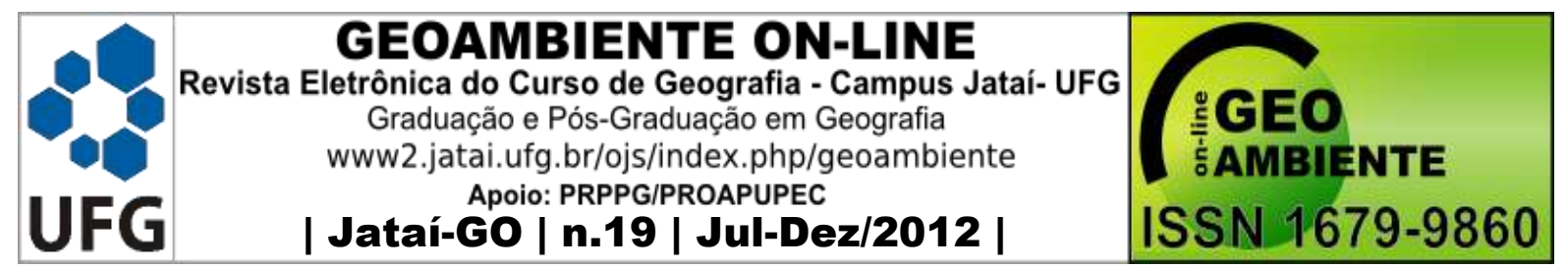

A umidade relativa do ar também se comportou de maneira oscilante durante o ano de 2009, tendo o mês de janeiro registrado o índice de 70\%; fevereiro, 74; março, 76; abril, 73; maio, 75; junho, 76; julho, 71; agosto, 62; setembro, 64; outubro, 68; novembro, 74 e dezembro, o índice de 70\%. Dessa forma, visualizou-se que os meses que apresentaram os maiores índices de umidade relativa do ar foram abril e junho, sendo registrada a umidade mais baixa no mês de agosto.

Ainda averiguando a (tabela 1), a precipitação se manifestou de forma variável durante o decorrer do ano, tendo as maiores somas chuvosas ocorrido nos meses de dezembro com 354,8; outubro com 175,6 e novembro 110,8mm. Assim ressaltamos que estes meses coincidem com o final da estação da primavera na transição para o verão onde as chuvas se intensificam com somas mais expressivas.

Tabela 1- dados climáticos e de dengue clássica referentes ao ano de 2009.

\begin{tabular}{|c|c|c|c|c|}
\hline Meses & $\begin{array}{c}\text { Temperatura } \\
\text { Média }^{\circ} \mathrm{C}\end{array}$ & $\begin{array}{l}\text { Umidade relativa } \\
\text { do ar \% }\end{array}$ & $\begin{array}{c}\text { Precipitação } \\
\text { mm }\end{array}$ & $\begin{array}{c}\text { Casos de Dengue } \\
\text { Clássica }\end{array}$ \\
\hline Janeiro & 27,5 & 70 & 106,0 & 63 \\
\hline Fevereiro & 27,6 & 74 & 98,0 & 160 \\
\hline Março & 27,6 & 76 & 100,0 & 569 \\
\hline Abril & 24,8 & 73 & 79,8 & 4.534 \\
\hline Maio & 25,5 & 75 & 47,7 & 3.121 \\
\hline Junho & 22,7 & 76 & 48,2 & 856 \\
\hline Julho & 24,1 & 71 & 29,9 & 398 \\
\hline Agosto & 25,9 & 62 & 88,0 & 156 \\
\hline Meses & $\begin{array}{c}\text { Temperatura } \\
\text { Média }^{\circ} \mathbf{C}\end{array}$ & $\begin{array}{c}\text { Umidade relativa } \\
\text { do ar \% }\end{array}$ & $\begin{array}{c}\text { Precipitação } \\
\text { mm }\end{array}$ & $\begin{array}{c}\text { Casos de Dengue } \\
\text { Clássica }\end{array}$ \\
\hline Setembro & 27,2 & 64 & 68,2 & 62 \\
\hline Outubro & 28,2 & 68 & 175,6 & 84 \\
\hline Novembro & 28,4 & 74 & 110,8 & 385 \\
\hline Dezembro & 28,0 & 70 & 354,8 & $\begin{array}{c}819 \\
11207\end{array}$ \\
\hline
\end{tabular}

Fonte: $9^{\circ}$ - DISME/INMET e SINAN/DATASUS

Organizador: Romário Rosa de Sousa (2011).

No mês de janeiro o valor de precipitação registrado foi de 106,0; em fevereiro, de 98 e em março, de $100 \mathrm{~mm}$. A partir do mês de abril os valores diminuem com registro de 79,8; em maio, com 47,7; em junho, com 48,2; em julho, com 29,9; em agosto, com 88,0; e setembro, com o registro de $68,2 \mathrm{~mm}$. Dessa forma, a partir do mês de abril inicia-se a estação do outono no Cerrado, ou seja, o período mais seco, tendo os meses de junho, julho e agosto o inverno somatórias de precipitação bem baixas ou até mesmo não havendo registro. 


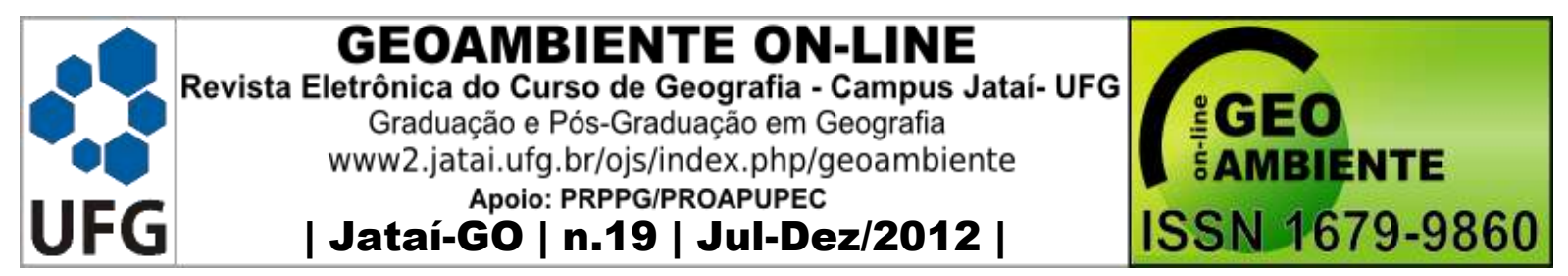

Diante de toda a variação climática ocorrida na área de estudo, percebeu-se que os casos de dengue clássica notificados também se comportaram de maneira variável de acordo com os condicionantes atmosféricos. O mês de janeiro apresentou 63 casos de dengue clássica; fevereiro, 160; março, 569; abril, 4.534, maio, 3.121; junho, 856, julho, 398; agosto, 156; setembro, 62; outubro, 84; novembro, 385 e dezembro, 819, totalizando, o ano de 2009, 11.207 notificações.

Constatou-se que nos meses de abril e maio, com 4.534 e 3.121 casos respectivamente, aconteceram as maiores somas de notificações relacionadas aos casos de dengue clássica registradas em Mato Grosso na cidade de Cuiabá, sendo que estes meses coincidem com o início do outono. Em seguida, os dados diminuem bruscamente nos meses de junho, julho, agosto, setembro, outubro, sendo que nos meses de novembro e dezembro as confirmações voltam a aumentar. Dessa forma visualizou-se na (Tabela 1) que os casos de dengue clássica variam de acordo com as condições atmosféricas.

Vale ressaltar que, temperaturas elevadas, umidade relativa do ar alta, precipitação abundante e depósitos artificiais e naturais são os elementos perfeitos para que o mosquito da dengue possa encontrar as condições ideais para a sua a proliferação (GONÇALVES-NETO \& REBELO 2004, SOUSA, 2008; SOUSA et al. 2010).

A temperatura tem grande influência nas atividades de hematofagia das fêmeas de Aedes aegypti, em sua longevidade e no período de incubação extrínseco do vírus. As temperaturas elevadas promovem um acelerado desenvolvimento das formas imaturas do mosquito, elevando também sua sobrevivência, o que não acontece em temperaturas baixas (Donalísio e Glasser 2002; Passos et al. 2003). Os decréscimos na ocorrência de dengue até chegar a zero nos meses de junho a outubro estão relacionados com as baixas precipitações e temperaturas que ocorrem nos citados meses. Assim, em algumas partes do Brasil, principalmente nas regiões Sudeste e no Centro-Oeste, com a chegada da estação fria, caem as temperaturas e a pluviosidade, acarretando uma redução no número de mosquitos, e conseqüentemente da transmissão da doença (PASSOS et al. 2003).

Averiguando a espacialização (Figura 4), em relação aos casos registrados por semanas para o ano de 2009, notou-se que a grande quantidade de casos de dengue ocorreu nas porções norte e oeste, sendo que as porções leste e sul apresentaram as menores somas.

$\mathrm{Na}$ análise dos dados referentes aos anos de 2001 a 2010 (Figura 5), averiguou-se, em relação aos dados de dengue clássica ocorridos em Cuiabá-MT até o ano de 2008, que 


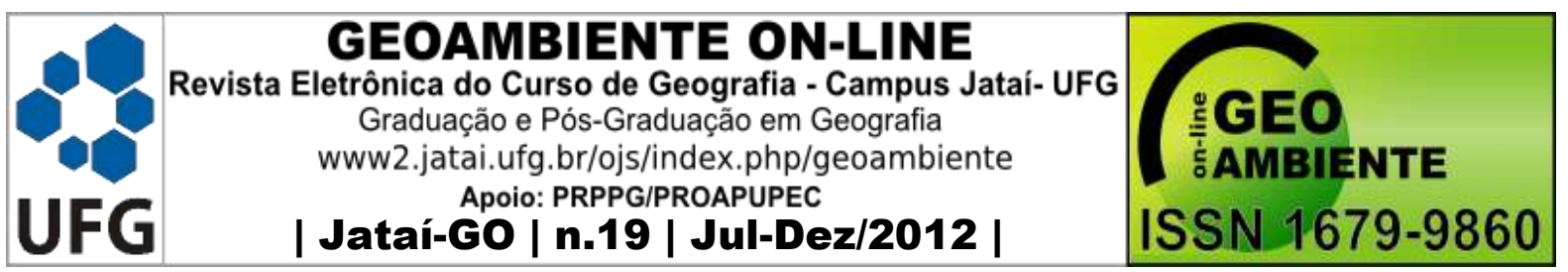

ocorreram de 2000(dois mil) a 4000(quatro mil) casos e, no ano de 2009, apresentou ainda um aumento significativo no número de casos que correspondeu ao surto da doença.

Figura 4 - notificações por semana epidemiológica de início de sintomas em 2009.

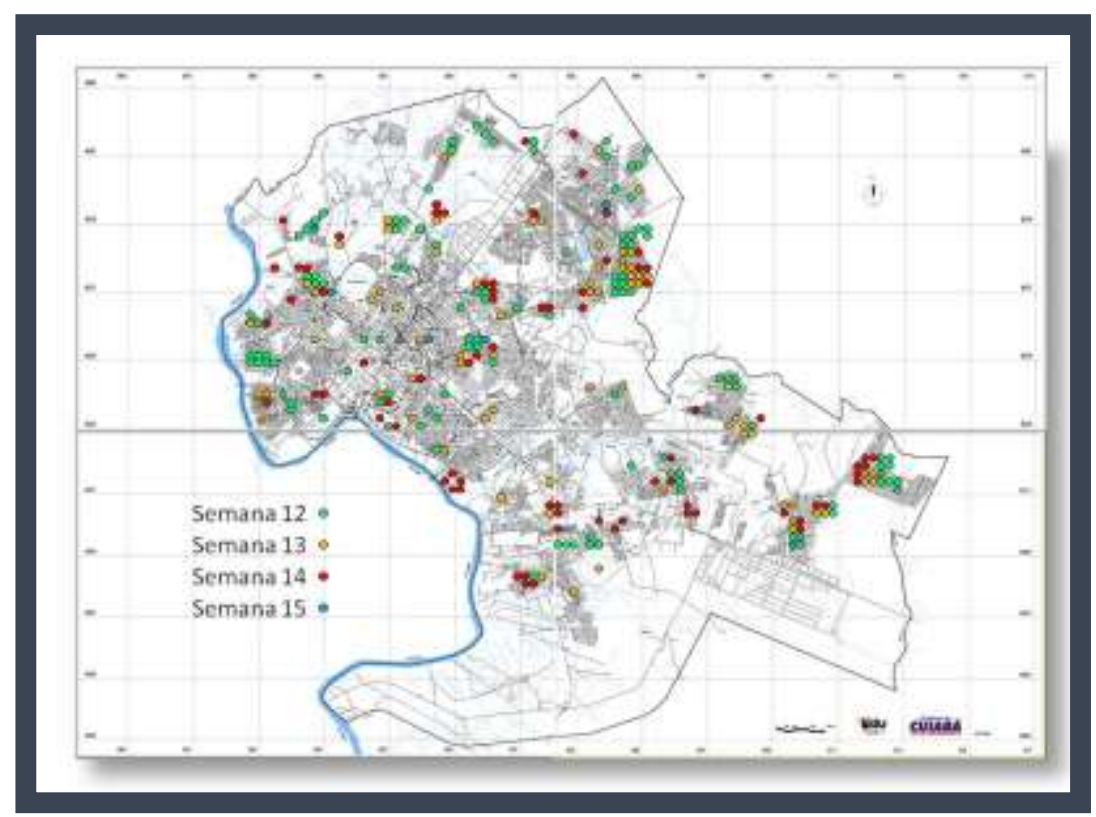

Fonte: CCZ/Sinan/Covidae/Gevidat (2009).

Figura 5 - casos anual de dengue em Cuiabá, de 2001 a 2010

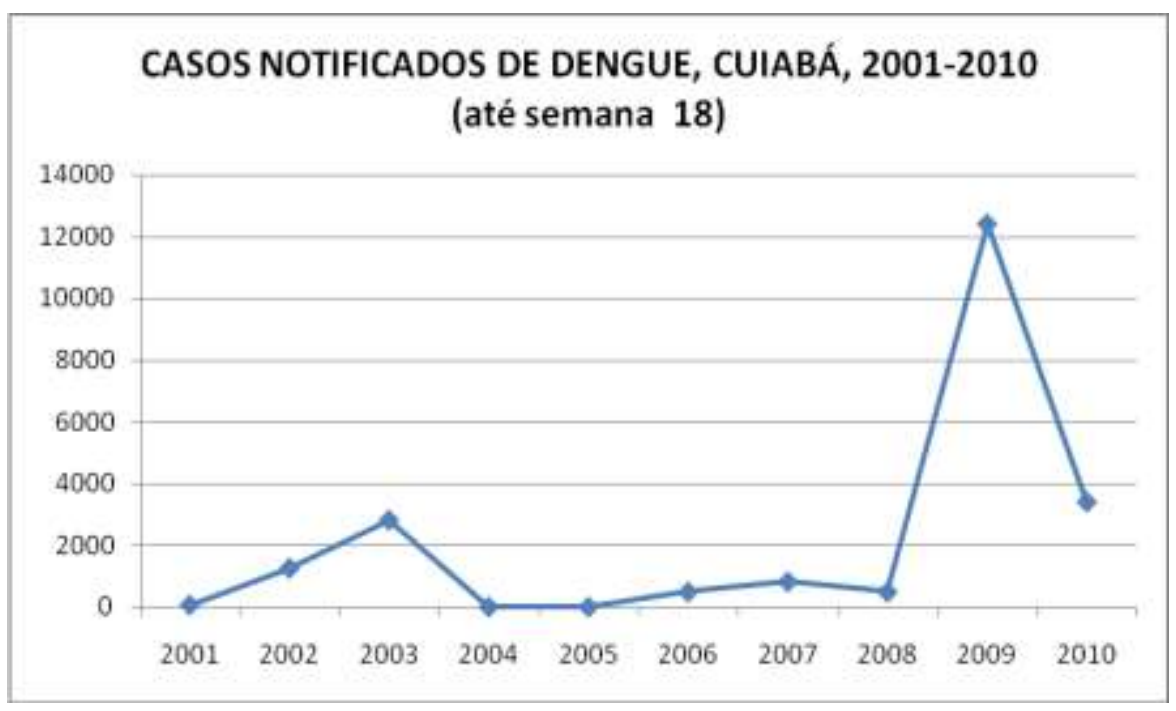

Fonte: Secretaria Municipal de Saúde do Município de Cuiabá - (SMS). 


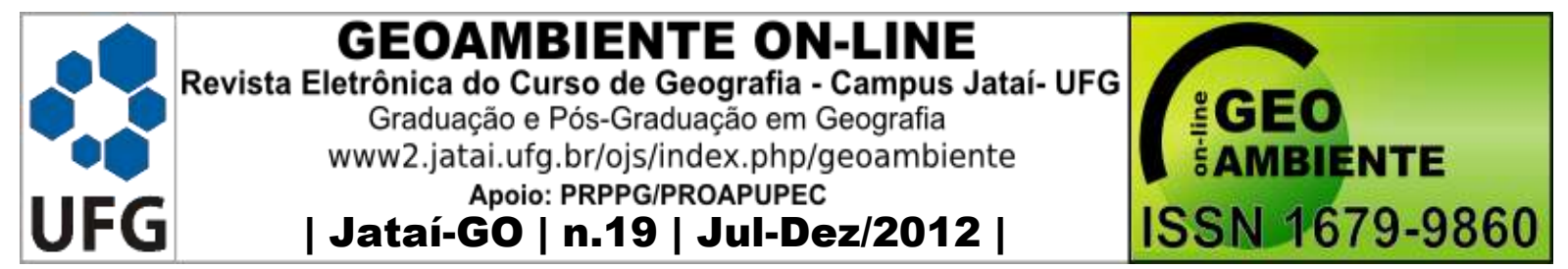

Neste contexto, de acordo com Secretaria Municipal de Saúde do Município de Cuiabá (SMS), foram totalizados, em toda a área urbana do município, 27.884 terrenos baldios, correspondendo a 12,2\% dos imóveis inspecionados pelo Centro de Controle de Zoonoses (CCZ) de Cuiabá - MT. Destes, 10.492 (37,6\%) terrenos estão na região sul, 7.991 (28,7\%), na região norte, 4.756 (17\%), na oeste e 4.645 (16,7\%), na região leste (CUIABÁ, 2009).

O percentual de imóveis positivos num total de imóveis visitados é o índice predial ou índice larvário (LI), principal indicador entomológico do Programa de Controle da Dengue em Cuiabá, preditivo do risco de ocorrência de casos, segundo classificação estabelecida pelo PNCD/MS, sendo $\leq$ (menor ou igual) a $1,0 \%$ : satisfatório; de $1,1 \%$ a 3,99\%: estado de alerta e $\geq$ (igual ou maior) a $4,0 \%$ : risco de epidemia.

A espacialização da média do índice larvário na área urbana do município (Figura 6), com base nos dados do primeiro ciclo de 2009 (janeiro a março), evidenciou que somente $15 \%$ dos bairros trabalhados tiveram LI satisfatório. Em $65 \%$ dos bairros, o índice larvário foi de estado de alerta, com predomínio na região leste e distribuição semelhante nas demais regiões. O índice de risco de epidemia ocorreu em $20 \%$ dos bairros trabalhados, com maior frequiência na região sul $(77,8 \%)$, seguida das regiões leste $(19,4 \%)$, oeste e norte $(2,8 \%$ cada).

Segundo (CUIABÁ, 2009), as regiões Norte e Sul possuem o maior número de bairros de perfil socioeconômico predominante nas faixas de baixa renda (menor que 2,91 salários mínimos) e média baixa (de 2,91 a 5,65 salários mínimos). Considerando-se que os fatores sociais funcionam como facilitadores ou empecilhos para a dispersão dos vírus em uma determinada área, estas regiões devem merecer atenção especial. Diante disso, analisando o perfil socioeconômico predominante nas faixas de baixa renda, com a espacialização dos índices larvários na área urbana do município (Figura 6), visualiza-se que a porção sul possui um risco de epidemia.

As condições socioeconômicas em que vivem as pessoas com baixa renda de escolaridade, também são fatores agravantes para a proliferação do mosquito da dengue, entretanto, diferentemente dos resultados apresentados, onde a classe baixa e de menor nível de escolaridade é acaba sendo afetados, estudos indicam também que notificações da doença em indivíduos de classe média alta, decorrente do costume de cultivar plantas em vasos, devido o grande consumos de objetos descartáveis (descartados em locais impróprios), além 


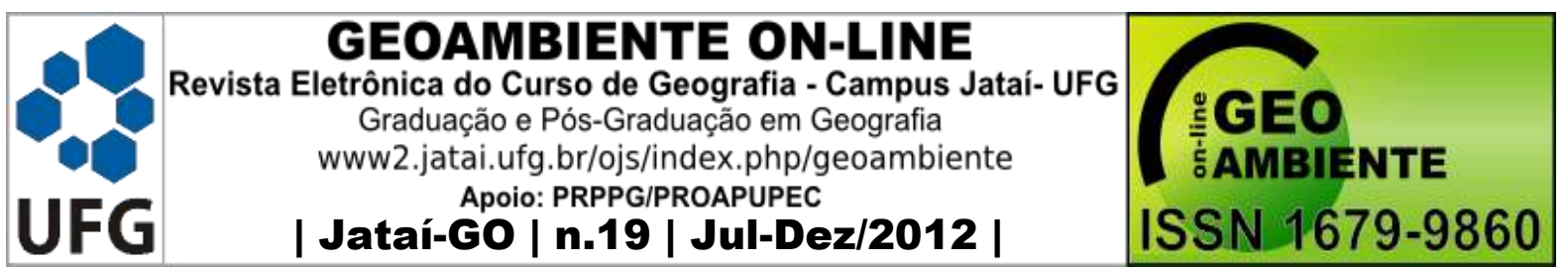

da grande quantidade de piscinas residenciais, os quais se tornam locais propícios para o desenvolvimento do mosquito vetor da dengue (RIBEIRO, et al 2008; SANTOS, et al 2009).

Figura 6 - percentual de imóveis com índices larvário 2009.

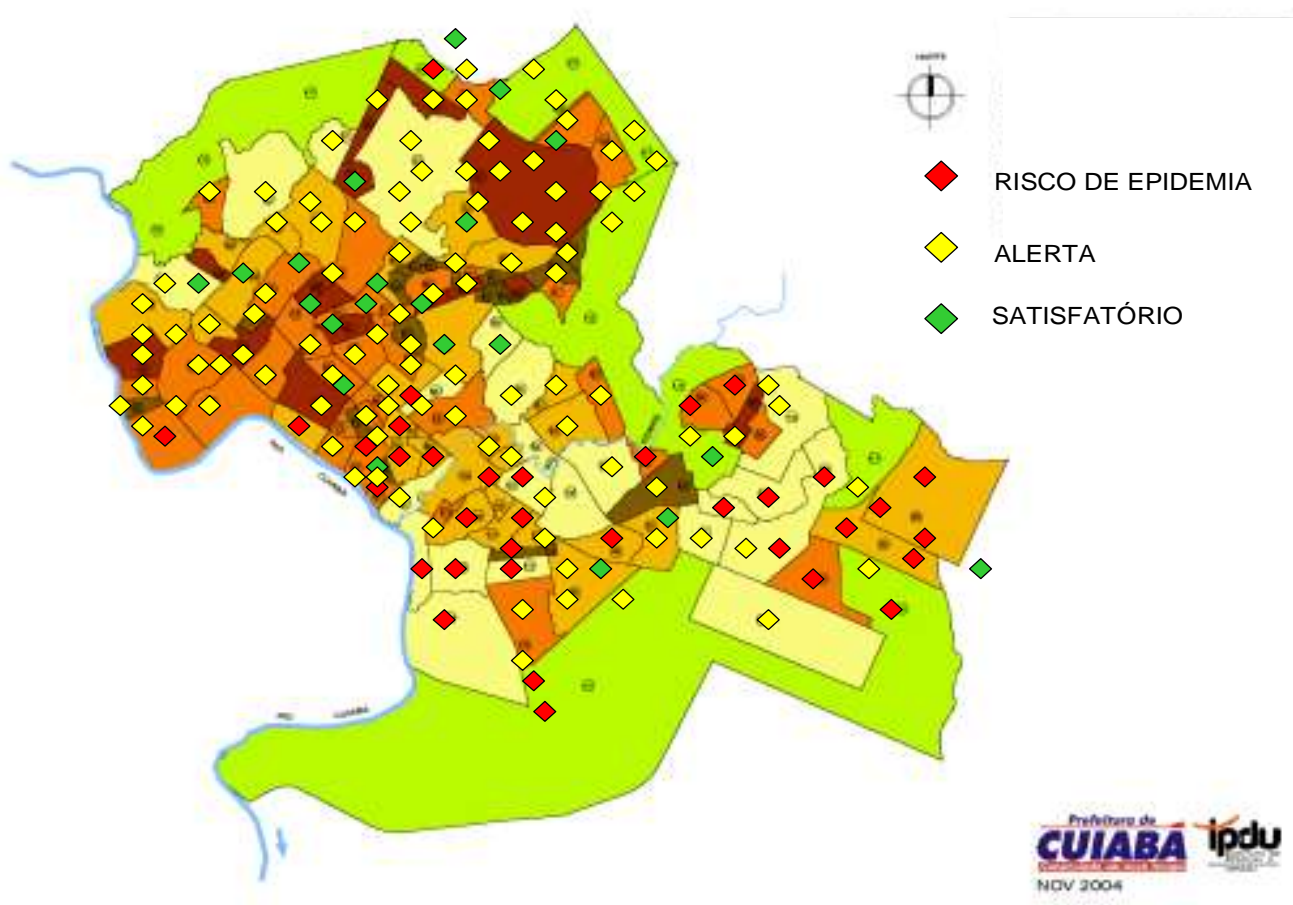

Fonte: Centro de Controle de Zoonoses - CCZ de Cuiabá - MT

Um aspecto crítico observado na cidade de Cuiabá-MT é o acumulo de lixo em terrenos baldios, oficinas mecânicas, borracharias, ferros velhos, às margens dos córregos e rios, onde foram verificados vários criadouros do mosquito Aedes aegypti. Os resíduos sólidos se transformam em um grande problema sanitário devido o fato de facilitarem a proliferação de organismos patogênicos e de muitos vetores relacionados na transmissão da doença (RIBEIRO, et al. 2008).

Donalísio e Glasser (2002), afirmam que, em uma diversidade de reservatórios naturais de água, como pedaços de bambus, floreiros em cemitérios, ocos de árvores, como de bromélias, reservatórios artificiais, como calhas de edificações, ralos e canaletas de drenagem pluvial são os criadouros preferenciais utilizados pelo mosquito Aedes aegypti.

De acordo com o Sistema Único de Saúde - SUS/Ministério da Saúde (2010) -, os estados e municípios brasileiros devem ficar sob alerta para o verão de 2010/2011, uma vez que dez estados brasileiros têm risco muito alto de enfrentar epidemia de dengue, nove têm 


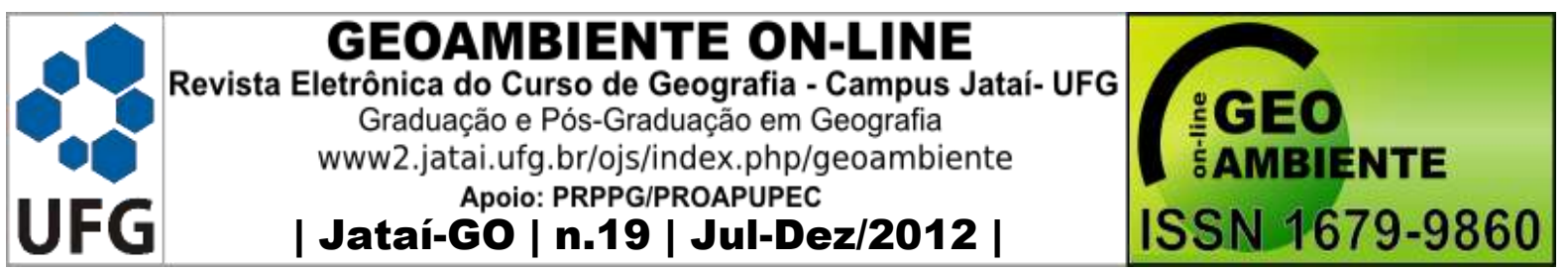

risco alto e outros cinco estados mais o Distrito Federal têm risco moderado (Figura 7). Podese observar que, na Região Centro-Oeste, o Estado de Mato Grosso, está inserido na zona de risco alto de epidemia de dengue para o ano de 2010/2011.

No Brasil, desde a década de 1980, a dengue tem sido endêmica e está associada a epidemias que introduziram novos sorotipos em áreas previamente não afetadas anteriormente. (BASTOS, 2004). Assim, as condições climáticas, juntamente com as péssimas ações governamentais de curto e longo prazo, apontam para a tendência de a dengue já ter se tornado uma doença endêmica principalmente em algumas regiões como no CentroOeste brasileiro.

Figura 7 - alerta verão risco de epidemia de dengue.

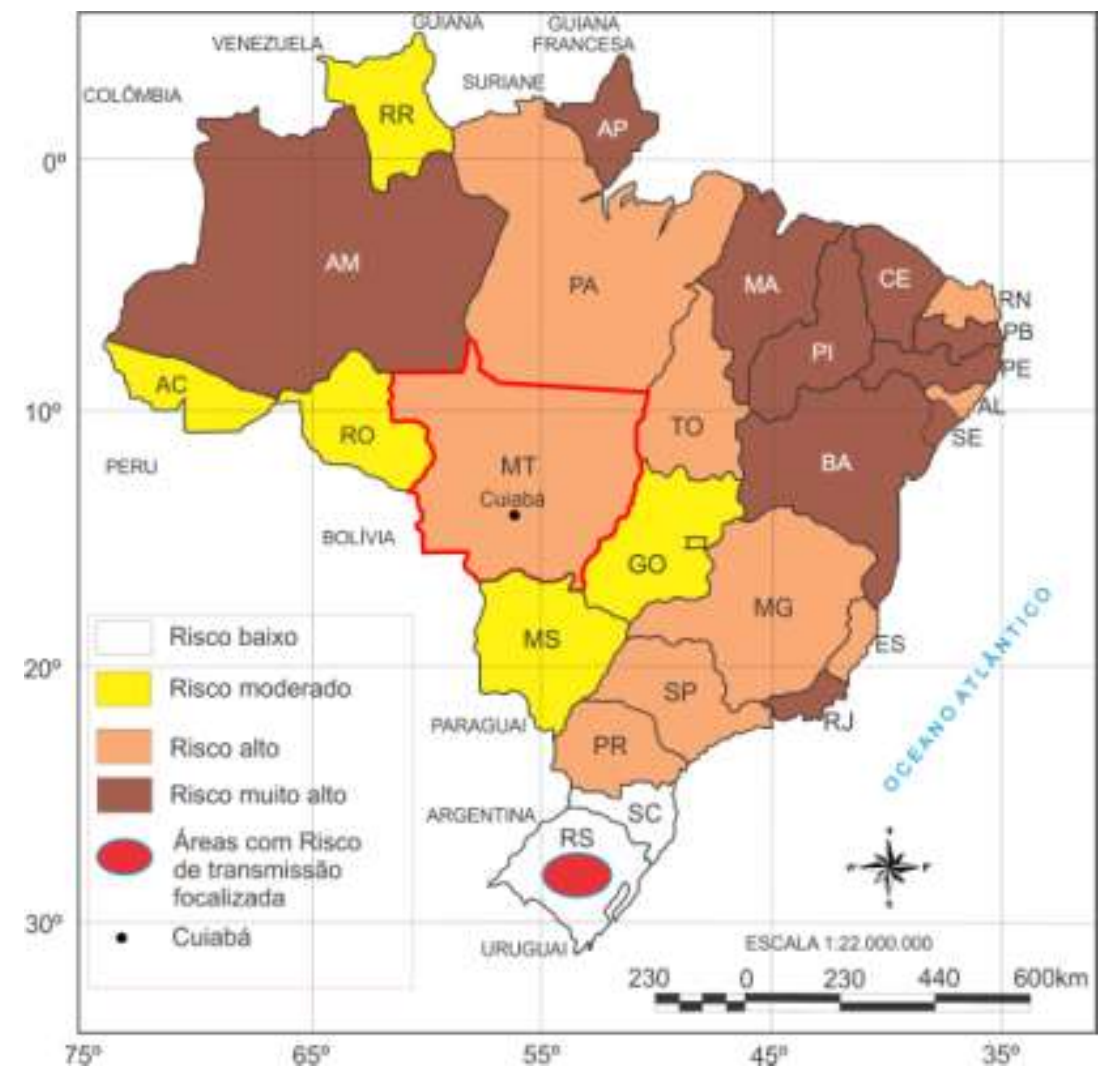

Fronte: Sistema Único de Saúde - SUS/Ministério da Saúde (2010)

Adaptado por Romário Rosa de Sousa (2012).

\section{Considerações Finais}

Diante do caos da maior epidemia de dengue registrada no Estado de Mato Grosso, na cidade de Cuiabá, a prefeitura local reestruturou o Programa Municipal de Controle da Dengue de Cuiabá-MT, iniciado com oficinas e debates. A partir das oficinas, a prefeitura 


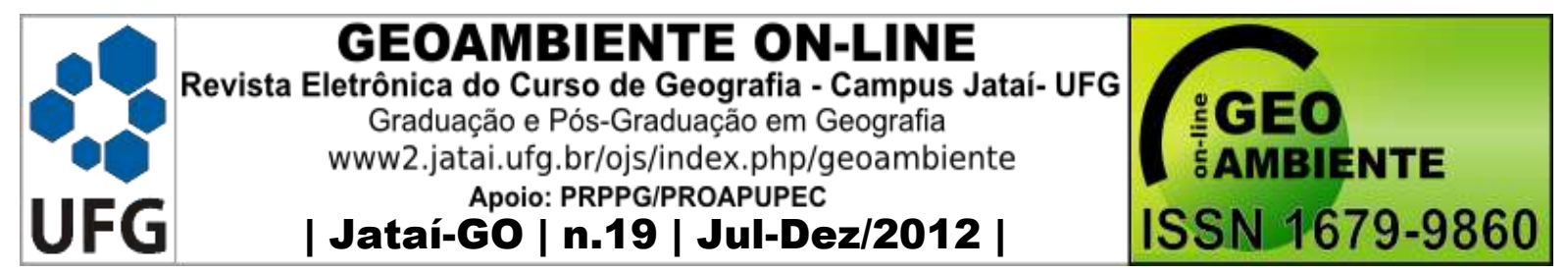

investiu na contratação e capacitação de profissionais, além de rever e uniformizar condutas entre os Distritos de Saúde e o Centro de Controle de Zoonoses (CCZ) e fortalecer a coordenação do programa tanto no nível municipal, como nos Distritos e CCZ.

A vigilância epidemiológica tem o importante papel de estimular os profissionais de saúde para detecção precoce de casos suspeitos, evitando, assim, epidemias de grandes dimensões, como aconteceu na cidade de Cuiabá no ano de 2009. É importante que toda a equipe esteja atenta à ocorrência de novos casos e à localização espacial do risco, para que as decisões sejam tomadas em tempo adequado ao controle da epidemia.

O diagnostico da situação da dengue no município de Cuiabá, focando as fragilidades, possibilitou identificar as áreas prioritárias para intervenção, lançando mão de ferramentas legais e técnicas que possibilitassem ações resolutivas, sobretudo pela oportunidade de sua realização. Conhecer os pontos fracos do programa de controle da dengue e, mais ainda, discuti-los amplamente são determinantes para o sucesso obtido no controle de uma epidemia, especialmente quanto à opção por novas estratégias que tragam mais visibilidade sobre as áreas de risco de transmissão da doença, os locais onde a transmissão se faz de forma emergente ou sustentada e a constatação de indicadores da baixa adesão da população às orientações emanadas pelos agentes de controle da dengue.

As ações governamentais de prevenção da dengue necessitam do envolvimento de outros setores da sociedade durante todo o ano, não apenas na época do verão, período de maior aparecimento da morbidade, e devem focalizar questões como a melhoria das condições de urbanização e de habitação, que compreendem a coleta regular de lixo, o abastecimento permanente de água e a educação da população.

\section{Referências}

BESANCENOT, J. P. Climat et santé. Paris: PUF, (Medicine et santé). 2001

BASTOS, M. S. Perfil soroepidemiológico do dengue diagnosticado na Fundação de Medicina Tropical do Amazonas (1998-2001). [Dissertação de Mestrado]. Escola Nacional de Saúde Pública, Rio de Janeiro, RJ, 2004. Disponível em: http://libdigi.unicamp.br. Acesso em março, 2012.

BRASIL - Fundação Nacional de Saúde. Instruções para pessoal de combate ao vetor: manual de normas técnicas. $3^{\circ}$ ed. Revisada. Brasília: MS: Fundação Nacional de Saúde, 84 p. 2001. 


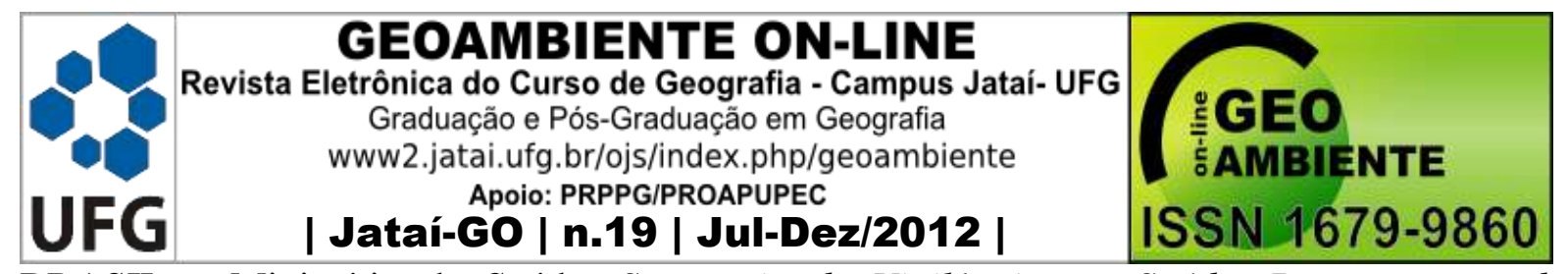

BRASIL - Ministério da Saúde. Secretaria de Vigilância em Saúde. Departamento de

Vigilância Epidemiológica. Diretrizes nacionais para prevenção e controle de epidemias de dengue, Ministério da Saúde, Brasília, 2009.

CUIABÁ - Secretaria de Meio Ambiente e Desenvolvimento. Instituto de Pesquisa e Desenvolvimento Urbano. Perfil sócio econômico do município de Cuiabá. Cuiabá: 2009.

CONSOLI R, Oliveira R. L. Principais Mosquitos de Importância Sanitária no Brasil. Rio de Janeiro, RJ: Editora Fiocruz, 1994. 228p. il.

CATÃO, R. C.; GUIMARÃES, R.F.; CARVAlHO JR, O. A.; GOMES, R. A. T. In: Simpósio Nacional de Geografia da Saúde 3. Fórum Internacional de Geografia da Saúde 1. Curitiba: Universidade Federal do Paraná. 08 a 11 outubro. Anais... Cd-rom. 2007.

DONALÍSIO, M. R. \& GLASSER, C. M. Vigilância entomológica e controle de vetores do dengue. Revista Brasileira de Epidemiologia 5: 259-272. 2002.

DONALISIO M.R. O dengue no espaço habitado. Ed Hucitec, SP, 1999.

GONÇALVES-NETO, V. S. \& J. M. M. REBELO. Aspectos epidemiológicos do dengue no município de São Luis-MA, 1997-2002. Caderno de Saúde Pública 20: 1424-1431.

GUNN, P. Saúde pública e as reformas de Paula Souza. In: JR-PHILIPPI, A.; ROMÉRIO, M. A. de.; BRUAN, G. C.(Org.). Curso de Gestão ambiental. Barueri: Manoele. p. 412-457. $1.446 \mathrm{p}$.

GUIMARÃES, R. B. Saúde pública e política urbana: memória e imaginário social. São Paulo: [Tese Doutorado], Universidade de São Paulo-USP. 2000.

MALVASI, H. G. Análise espacial da epidemia de dengue em Campinas/SP no ano de 2007. [Dissertação Mestrado] - Universidade Estadual de Campinas, Campinas, 2007. Disponível em: http://libdigi.unicamp.br. Acesso em março, 2012.

MENDONÇA, F. A. Aquecimento global e saúde: Uma perspectiva geográfica - Notas introdutórias São Paulo-SP: Revista Terra Livre. n 20, Associação dos Geógrafos Brasileiros-Diretório Nacional/AGB-DN, 2003.

MATO GROSSO. Secretaria de Estado de Saúde. Dados básicos sobre dengue no Mato Grosso. Cuiabá. Coordenadoria de Vigilância Epidemiológica/Superintendência de Vigilância em Saúde, 2009.

NERES, I. A. S. Controle do dengue: caracterização dos criadouros de Aedes aegypti (Díptera, Culicidae) e participação das mulheres nas campanhas de prevenção em CaxiasMA. São Luis: Universidade Federal do Maranhão. Dissertação (Mestrado) - Programa de 


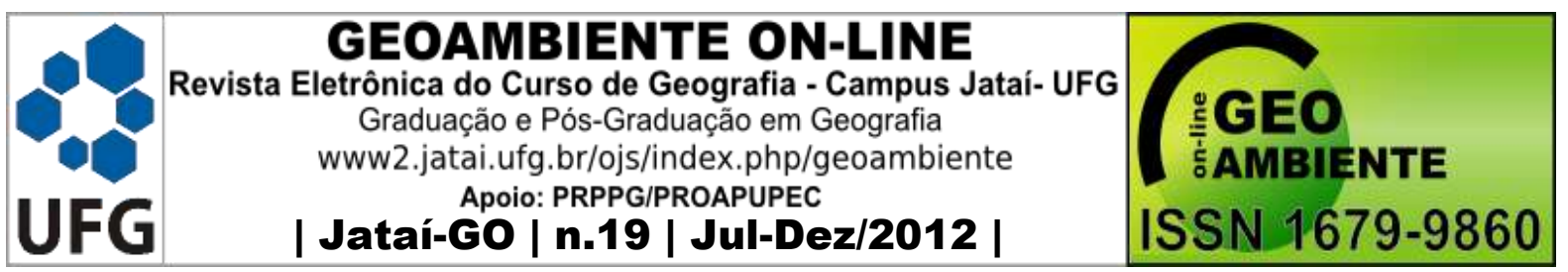

Pós-graduação em Saúde Materno-Infantil, Centro de Ciências Biológicas e da Saúde.73 p. 2009.

PASSOS, R. A.; MARQUES, G. R. A. M.; VOLTONI, J. C. \& CONDINO, M. L. F. Dominância de Aedes aegypti sobre albopictus no litoral sudeste do Brasil. Revista de Saúde Pública 37. 729-734 p. 2003.

PIMENTA JUNIOR, F. G. Desenvolvimento e validação de um instrumento para avaliar o Programa Nacional de Controle da Dengue no âmbito municipal. Brasília. Dissertação (Mestrado Profissional em Vigilância em Saúde). ENSP/FIOCRUZ. 210p. 2004.

PIGNATTI, M.G. Saúde e ambiente: as práticas sanitárias para o controle do dengue no Estado de São Paulo (1985-1995). [Dissertação de Mestrado] Campinas, 1996.

PESSOA, S.B. Ensaios Médico-Sociais. São Paulo: CEBES/Editora Hucitec; 1978.

RIBEIRO, P. C.; SOUSA, D. C.; SOUSA \& ARAÚJO, T. M. E. Perfil clínico épidemiológico dos casos suspeitos de dengue em um bairro da zona sul de Teresina-PI. Revista Brasileira de Enfermagem 61. 227-232 p. 2008.

ROSSI G. C; Pascual N.T; Krsticevic F.L. First record of Aedes albopictus (Skuse) from Argentina. J Am Mosq Control Assoc. 15(3): 422.1999.

SANTOS, C. H.; SOUSA, F. Y. LIMA, L. R. \& STIVAL, M. M. Perfil epidemiológico do dengue em Anápolis-GO. 2001-2007. Revista de Patologia Tropical. 38. 249-259 p. 2009.

SISTEMA ÚNICO DE SAÚDE - SUS. Ministério da Saúde lança ferramenta para avaliar risco de epidemias de dengue: Disponível em http://portal.saude.gov.br/portal/aplicacoes/noticias/default.cfm?pg=dspDetalheNoticia\&id_a ea=124\&CO_NOTICIA=11674 acesso em 23/10/2010.

SILVA, L.J. O conceito de espaço na epidemiologia das doenças infecciosas. Cadernos de Saúde Pública. v. 13 p. 585-93 p. 1997.

SOUSA, R. R. de. A propósito de um mapeamento da epidemia de dengue na cidade de Cuiabá, MT. Goiânia: Revista Geografia Acadêmica. n. 1. v. 2. 73-87 p. 2008.

SOUZA, S. S.; I. G; SILVA \& H. H. G. SILVA. Associação entre a incidência de dengue, pluviosidade e densidade larvária de Aedes aegypti, no Estado de Goiás. Revista da Sociedade Brasileira de Medicina Tropical 43: 152- 155.

TAUIL, P. L. Aspectos críticos do controle do dengue no Brasil. Cad. Saúde Pública, Rio de Janeiro, 18(3):867-71, mai-jun, 2002. 